\title{
Association between peripheral blood/ bronchoalveolar lavage eosinophilia and significant oxygen requirements in patients with acute eosinophilic pneumonia
}

\author{
Joon Young Choi ${ }^{1 \dagger}$, Jeong Uk Lim ${ }^{2 \dagger}$, Ho Jung Jeong ${ }^{3}$, Ji Eun Lee ${ }^{3}$ and Chin Kook Rhee ${ }^{2^{*}}$ (D)
}

\begin{abstract}
Background: We investigated the association between a combination of two markers, peripheral (PEC) and bronchoalveolar lavage (BAL) eosinophil percentage (BEP), and oxygen requirements in patients with acute eosinophilic pneumonia (AEP).

Methods: We retrospectively reviewed the medical records of patients with AEP treated at the Armed Forces Capital Hospital between May 2012 and May 2017. We used correlation analyses to assess the association between PEC/BEP and clinical outcomes in AEP patients. Receiver operating characteristic (ROC) curve analyses were used to calculate the cut-off value for BEP that categorised patients requiring a significant oxygen supply. The BAL/blood eosinophil (BBE) score was introduced to stratify patients with peripheral eosinophilia and elevated BEP. Clinical characteristics and outcomes were compared between the different groups. Multiple logistic regression was performed for significant oxygen requirements using two different models using age, C-reactive protein (CRP), smoking duration, and BBE score (model 1) and age, CRP, BEP, and PEC (model 2).
\end{abstract}

Results: Among the 338 patients, $99.7 \%$ were male, and their mean age was $20.4 \pm 1.4$ years. Only $0.6 \%$ of patients were never smokers and the mean number of smoking days was $26.2 \pm 25.4$. Correlation analyses revealed that both the $\mathrm{PaO}_{2} / \mathrm{FiO}_{2}$ ratio and duration of oxygen supply were associated with BEP. ROC curve analyses indicated a cut-off level of $41.5 \%$. Patients with a high BBE score had favourable outcomes in terms of hypoxemia, hospital days, intensive care unit admission, oxygen supply days, and steroid treatment days. Multiple logistic regression revealed that BEP and BBE score tended to be associated with significant oxygen requirements.

Conclusions: In this study, we revealed that both peripheral and BAL eosinophilia is associated with favourable outcomes in AEP patients.

Keywords: Acute eosinophilic pneumonia, Eosinophilia, Retrospective study

\section{Background}

Acute eosinophilic pneumonia (AEP) is an infrequent inflammatory lung disease of unknown aetiology [1, 2], which is accompanied by acute respiratory symptoms and diffuse pulmonary infiltration by eosinophils, among other issues [3-5]. The initial clinical presentation and

\footnotetext{
*Correspondence: chinkook77@gmail.com

${ }^{\dagger}$ Joon Young Choi and Jeong Uk Lim contributed equally to this work.

${ }^{2}$ Division of Pulmonary, Allergy and Critical Care Medicine, Department of Internal Medicine, Seoul St. Mary's Hospital, College of Medicine, The Catholic University of Korea, Seoul, Republic of Korea

Full list of author information is available at the end of the article
}

clinical course of AEP can differ from a mild respiratory disease that resolves spontaneously to acute respiratory distress syndrome [6, 7].

In previous studies from our centre, the Army Forces Capital Hospital (AFCH), a military hospital in Korea in which more than 70 patients with AEP are diagnosed annually [8-10], an association between elevated peripheral eosinophil count (PEC) and milder disease severity in AEP was demonstrated [11, 12]. Patients with initial peripheral eosinophilia had significantly higher oxygen saturation and

(c) The Author(s). 2020 Open Access This article is distributed under the terms of the Creative Commons Attribution 4.0 International License (http://creativecommons.org/licenses/by/4.0/), which permits unrestricted use, distribution, and reproduction in any medium, provided you give appropriate credit to the original author(s) and the source, provide a link to the Creative Commons license, and indicate if changes were made. The Creative Commons Public Domain Dedication waiver (http://creativecommons.org/publicdomain/zero/1.0/) applies to the data made available in this article, unless otherwise stated. 
a shorter duration of oxygen treatment compared to patients without peripheral eosinophilia [12].

In addition to peripheral eosinophilia, the correlation between eosinophilia in bronchoalveolar lavage (BAL) fluid and clinical outcomes of AEP has also been evaluated. Previous studies have shown that patients with higher average BAL eosinophil counts (BEPs) have a higher arterial oxygen tension $\left(\mathrm{PaO}_{2}\right)$ /inspiratory oxygen fraction $\left(\mathrm{FiO}_{2}\right)$ ratio $[5,12]$. Furthermore, hypoxemia is less severe in patients with higher BEP [13]. Although separate associations between peripheral blood eosinophil counts (PECs) and BEPs and AEP severity have been demonstrated in previous studies, a combination of these two markers may have superior predictive value for clinical outcomes for such patients.

Hence, in this study, we evaluated the clinical characteristics and outcomes of patients who were diagnosed with AEP at the AFHC during the last 5 years.

\section{Methods}

\section{Study patients}

All consecutive patients diagnosed with AEP at the AFCH (tertiary referral military hospital with 874 beds in South Korea) between May 2012 and May 2017 were retrospectively reviewed.

The AFCH is the highest ranking Korean military hospital where all military personnel in need of bronchoscopy are transferred from smaller hospitals including The Armed Forces Busan Hospital, The Armed Forces Cheongpyeong Hospital, and 14 other military hospitals.

Medical records from the electronic medical records (EMR) system and picture archiving and communication system (PACS) were reviewed to confirm AEP cases. Diagnoses were made according to previously proposed criteria as follows: acute-onset febrile respiratory manifestations $<1$ month in duration, bilateral diffuse infiltrates observed in chest radiographs, $>25 \%$ eosinophils in BAL fluid or eosinophilic pneumonia according to a lung biopsy, and absence of a known cause of pulmonary eosinophilia, including infections, toxins, and drugs [5]. We also included patients who did not undergo BAL or a lung biopsy, and diagnosed AEP by clinical impressions, radiological findings, and peripheral blood test results [10].

\section{Data collection}

We retrospectively collected data from the EMR including general baseline characteristics, detailed smoking history including smoking duration, hospital days, intensive care unit (ICU) admission days, oxygen requirements, initial treatments, and laboratory data including white blood cell (WBC) counts, eosinophil differentials (both blood and BAL fluid), C-reactive protein (CRP) levels, and $\mathrm{PaO}_{2} / \mathrm{FiO}_{2}$ ratio. We also reviewed the PACS to identify chest radiographic findings, including pulmonary infiltrates and pleural effusion.

\section{Study endpoints}

The primary endpoint of our study was total days of oxygen supply during admission, and we further determined which baseline parameters were associated with significant oxygen requirements (total days of oxygen supply $\geq 2$ days after admission) and also evaluated if blood eosinophil (\%) and peripheral eosinophil count show significant correlation with total days of oxygen supply.

\section{Definition of cigarette smoking duration}

Considering the unique background of patients included in our cohort, we only counted recent smoking experience. All enrolled patients were military personnel who must undergo basic military training upon entrance to the military. Smoking is strictly prohibited during basic military training of at least 6 weeks. We only evaluated smoking experience after basic military training regardless of past smoking experience.

\section{Oxygen supply}

Oxygen was prescribed to achieve a target saturation of 94-98\% [14]. If the patients' oxygen saturation was not maintained at the optimal level (94-100\%) despite oxygen supply by a nasal cannula or mask, oxygen was supplied by a high-flow nasal cannula (HFNC) [15].

Due to a risk of hypoxemia while obtaining BAL fluid, supplemental oxygen was given to the patients during bronchoscopy [16]. To exclude the possibility of including procedural- related oxygen supplementation, which we did not consider significant if the total duration of oxygen supply was only 1 day, and we defined "significant oxygen requirement" as total days of oxygen supply $\geq 2$ days after admission.

\section{BAL/blood eosinophil scoring (BBE score)}

Using receiver operating characteristic (ROC) curve analyses, BEP was categorised using the calculated cut-off after plotting whether a patient required an additional oxygen supply. Patients were stratified into three groups by the initial PEC and BEP. Patients who underwent BAL analyses were categorised into high and low BEP groups. Patients were categorised by PEC using a cut-off of $500 \times 10^{9}$ cells/L according to a previous study [8]. Patients with both high BEP and high PEC were given a score of 2. Patients with either a high BEP or PEC were given a score of 1 . Patients with no increase in either $\mathrm{BEP}$ or PEC were given a score of 0 . 


\section{Statistical analyses}

Statistical analyses were performed using SAS 9.3 software (SAS Institute, Cary, NC, USA). Quantitative variables are presented as means \pm standard deviations, and categorical variables are shown as numbers and percentages. Categorical variables, including sex, presence of a smoking history, ICU admission history, mechanical ventilation, HFNC, bilateral lung infiltrates, pleural effusion, and use of corticosteroids were compared between the groups using a chi-square test. Continuous variables, including age, number of cigarette smoking days, WBCs, PEC/BEP, CRP, hospital days, ICU admission days, oxygen supply days, and corticosteroid treatment duration were assessed using Student's $t$-test. We performed correlation analyses to demonstrate the correlations between $\mathrm{BEP}$ and the $\mathrm{PaO}_{2} / \mathrm{FiO}_{2}$ ratio, oxygen supply days, and PEC. We performed multiple logistic regression on significant oxygen requirement with two different models using age, C-reactive protein (CRP), smoking duration, and BBE score (model 1) and age, CRP, BEP, and PEC (model 2).

\section{Results}

\section{Clinical characteristics}

A total of 338 patients with AEP were evaluated. Of all, $253(74.9 \%)$ patients underwent BAL and 221 (65.4\%) patients had eosinophil percentage more than $25 \%$. Beside these patients, 117 (34.6\%) patients were diagnosed as AEP on basis of clinical and radiological context. As there was no patient who underwent lung biopsy, no patient was diagnosed by pathologic confirmation. Table 1 shows the general clinical characteristics of the patients. All but one patient was male (99.7\%), and their mean age was 20.4 years. Only two patients were never smokers. Mean total number of cigarette smoking days was 26.2. Mean WBC level was 14,359. Mean PEC, BEP, and CRP levels were 4.1, 46.7\%, and 9.4, respectively. About $37 \%$ of patients were initially admitted to the ICU, and mean hospital days, ICU admission days, and oxygen supply days were $10.5,2.0$, and 2.8 , respectively. Three patients underwent mechanical ventilation and nine patients were oxygenated with HFNC during ICU care. The initial chest radiograph findings revealed 94.1\% bilateral infiltrates and 51.2\% bilateral effusion. As an initial treatment, $76.9 \%$ of patients underwent intravenous corticosteroid therapy, $18.9 \%$ underwent oral corticosteroid therapy, and $4.1 \%$ did not receive steroids. The mean duration of steroid treatment was 14.2 days.

\section{Correlation between BEP and other significant parameters} The correlation analyses showed significant but weak correlations between the variables. BEP had a linear increasing relationship with the $\mathrm{PaO}_{2} / \mathrm{FiO}_{2}$ ratio (Pearson's correlation coefficient $r=0.207, P=0.008$ )
Table 1 Clinical characteristics of the 338 study patients

\begin{tabular}{|c|c|}
\hline Clinical parameters & Number \\
\hline Sex (male) $(n, \%)$ & $337(99.7)$ \\
\hline Mean age (SD) & $20.4 \pm 1.4$ \\
\hline \multicolumn{2}{|l|}{ Smoking history } \\
\hline Ever smoker & $336(99.4)$ \\
\hline Never smoker & $2(0.6)$ \\
\hline Cigarette smoking days & $26.2 \pm 25.4$ \\
\hline WBC & $14,359.3 \pm 5562.0$ \\
\hline Peripheral eosinophil (\%) & $4.1 \pm 5.7$ \\
\hline BAL eosinophil (\%) & $46.7 \pm 17.7$ \\
\hline CRP & $9.4 \pm 5.3$ \\
\hline Hospital days & $10.5 \pm 4.6$ \\
\hline ICU admission & $126(37.3)$ \\
\hline ICU admission days $(n=126)$ & $2.0 \pm 1.3$ \\
\hline Mechanical ventilation & $3(0.9)$ \\
\hline HFNC & $9(2.7)$ \\
\hline Oxygen supply days & $2.8 \pm 1.5$ \\
\hline \multicolumn{2}{|l|}{ Chest Radiograph Findings } \\
\hline Bilateral infiltrates & $318(94.1)$ \\
\hline No effusion & $122(36.1)$ \\
\hline Unilateral effusion & $41(12.1)$ \\
\hline Bilateral effusion & $173(51.2)$ \\
\hline \multicolumn{2}{|l|}{ Initial treatment } \\
\hline No steroid treatment & $14(4.1)$ \\
\hline Oral corticosteroid & $64(18.9)$ \\
\hline Intravenous corticosteroid & $260(76.9)$ \\
\hline Steroid treatment duration $(n=321)$ & $14.2 \pm 4.3$ \\
\hline
\end{tabular}

Abbreviations: BAL Bronchoalveolar lavage, CRP C-reactive protein, HFNC Highflow nasal cannula, ICU Intensive care unit, $S D$ Standard deviation, WBC White blood cell

(Fig. 1a). In addition, the number of oxygen supply days had a linearly decreasing relationship with BEP (Pearson's correlation coefficient $r=-0.202, P=0.005$ ) (Fig. 1b). PEC had a linearly increasing relationship with BEP (Pearson's correlation coefficient $r=0.276, P<0.001$ ) (Fig. 1c) and a linearly decreasing relationship with the number of oxygen supply days (Pearson's correlation coefficient $r=-0.157, P=0.014$ ) (Fig. 1d).

\section{Comparison between groups stratified by the BBE score}

A total of 244 patients had both an initial complete blood count and BAL results for evaluation. The optimal cut-off of BEP for prediction of significant oxygen supply requirement was calculated using ROC curve analysis. (Fig. 2). The area under the ROC curve was 0.577 with a $P$-value of 0.04 . The calculated cut-off was $41.5 \%$ for BEP. 

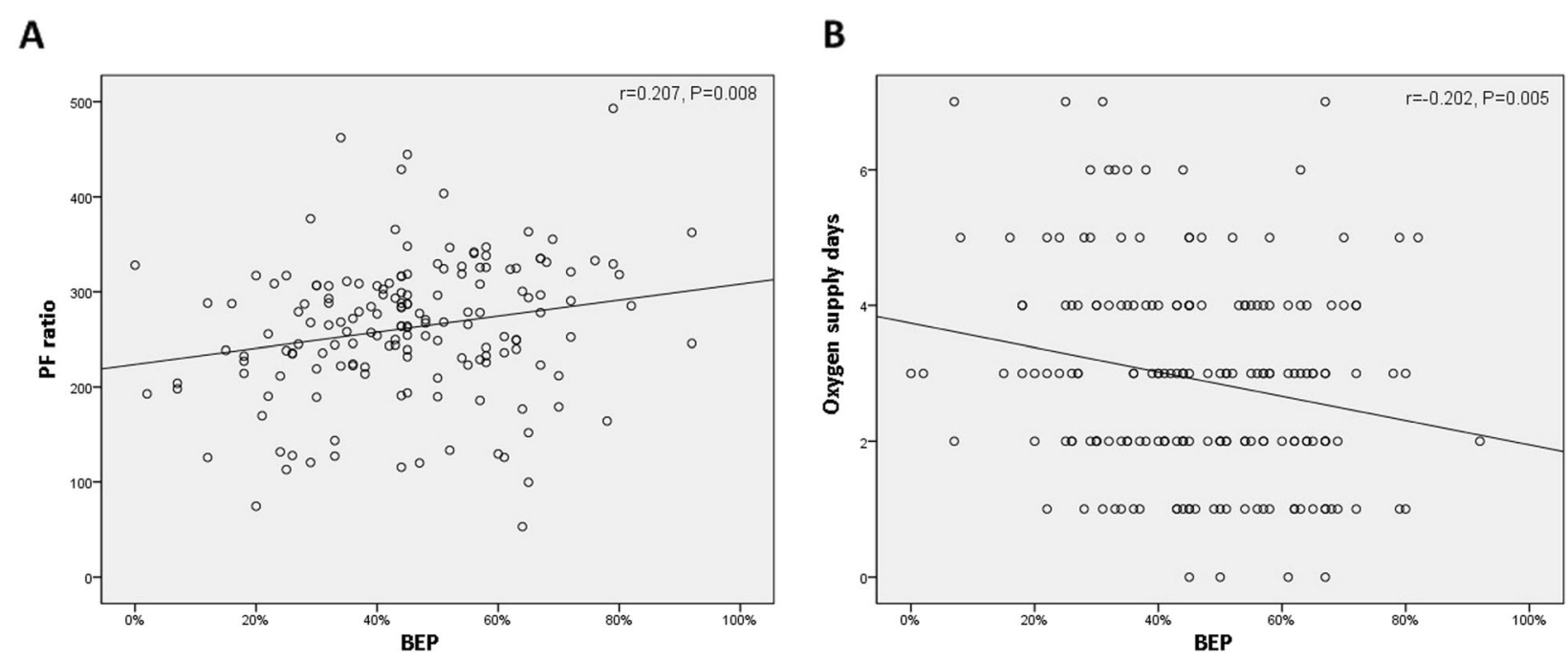

C

D
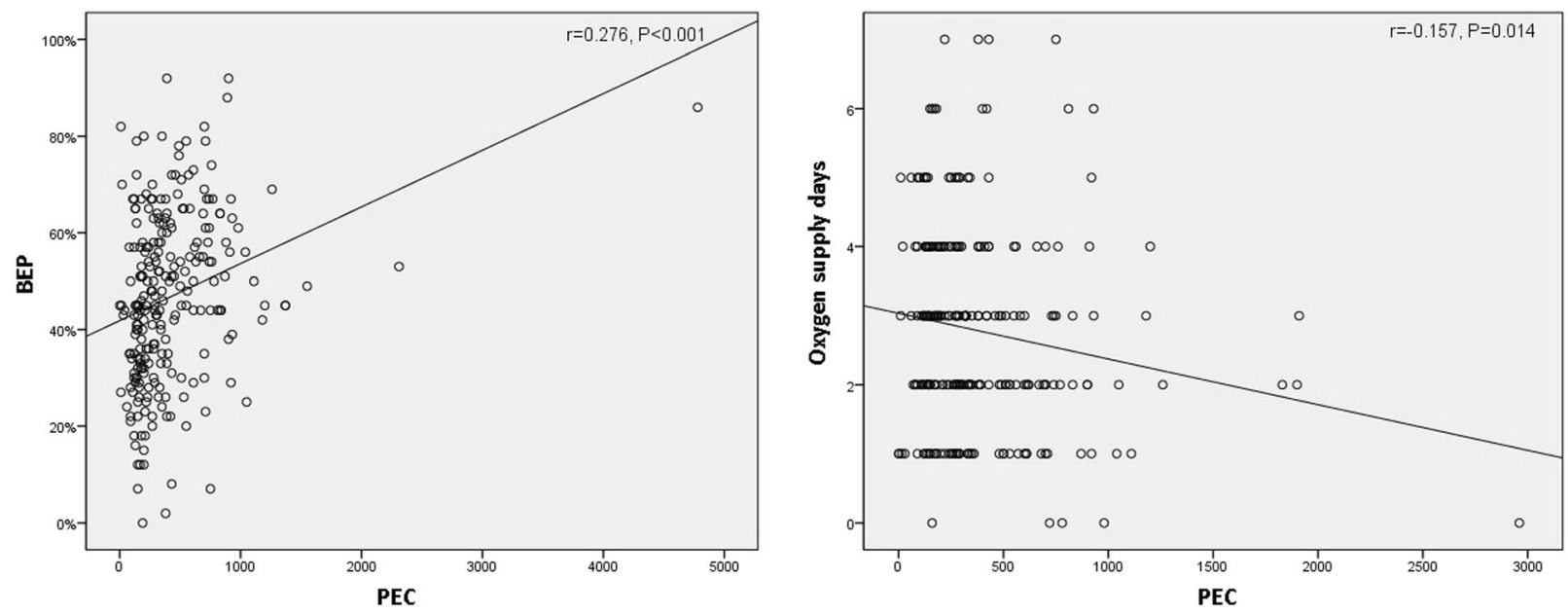

Fig. 1 Correlation analyses between eosinophilia and significant clinical parameters; (a) $\mathrm{PaO}_{2} / \mathrm{FiO}_{2}$ and $\mathrm{BEP}$; (b) oxygen supply days and $\mathrm{BEP}$; (c) BEP and PEC; (d) number of oxygen supply days and PEC. PF ratio: PaO2/FiO2; BEP: bronchoalveolar lavage (BAL) eosinophil percentage; PEC: peripheral eosinophil count

The baseline clinical characteristics of the 244 patients are shown in Table 2. Mean WBC, PEC, BEP, and CRP were $14,231,3.8,46.8 \%$, and 9.5 , respectively. The mean number of hospital days was 11.0 and ICU admission days was 2.0. The mean $\mathrm{PaO}_{2} / \mathrm{FiO}_{2}$ ratio at admission was 261.9. After stratification by BBE score, 78 patients were in group with score 0,108 patients were in group with score 1, and 58 were in group with score 2 . Male proportion and mean age were not different between the groups. The proportion of ever smokers and the mean number of smoking days were not significantly different.

WBCs were significantly different between the groups. The mean WBC decreased with an increase in the BBE score. The values were $16,248,14,489$, and 11,037 for groups with score 0,1 , and 2 , respectively $(P<0.001)$. Both mean PEC and BEP increased significantly as the score increased from 0 to $2(P<0.001$ and $P<0.001$, respectively). CRP was inversely related with the score $(P<0.001)$. The mean number of hospital days decreased significantly as the score increased from 0 to $2(P=$ 0.009) (Fig. 3a). The proportion of patients who were admitted to the ICU was significantly lower in group with score 2 than in group with score $0(P<0.001)$. The mean duration of ICU stay was not significantly different between the groups $(P=0.731)$.

A higher proportion of patients was given additional oxygen as the score decreased from 2 to $0(P=0.031)$. Two patients in group with score 0 and 1 patient in group with score 1 were mechanically ventilated, but no one in group with score 2 underwent mechanical ventilation. The mean total number of days of oxygen supply was $3.4,2.8$, and 2.3 in groups with score 0,1 , and 2 , 


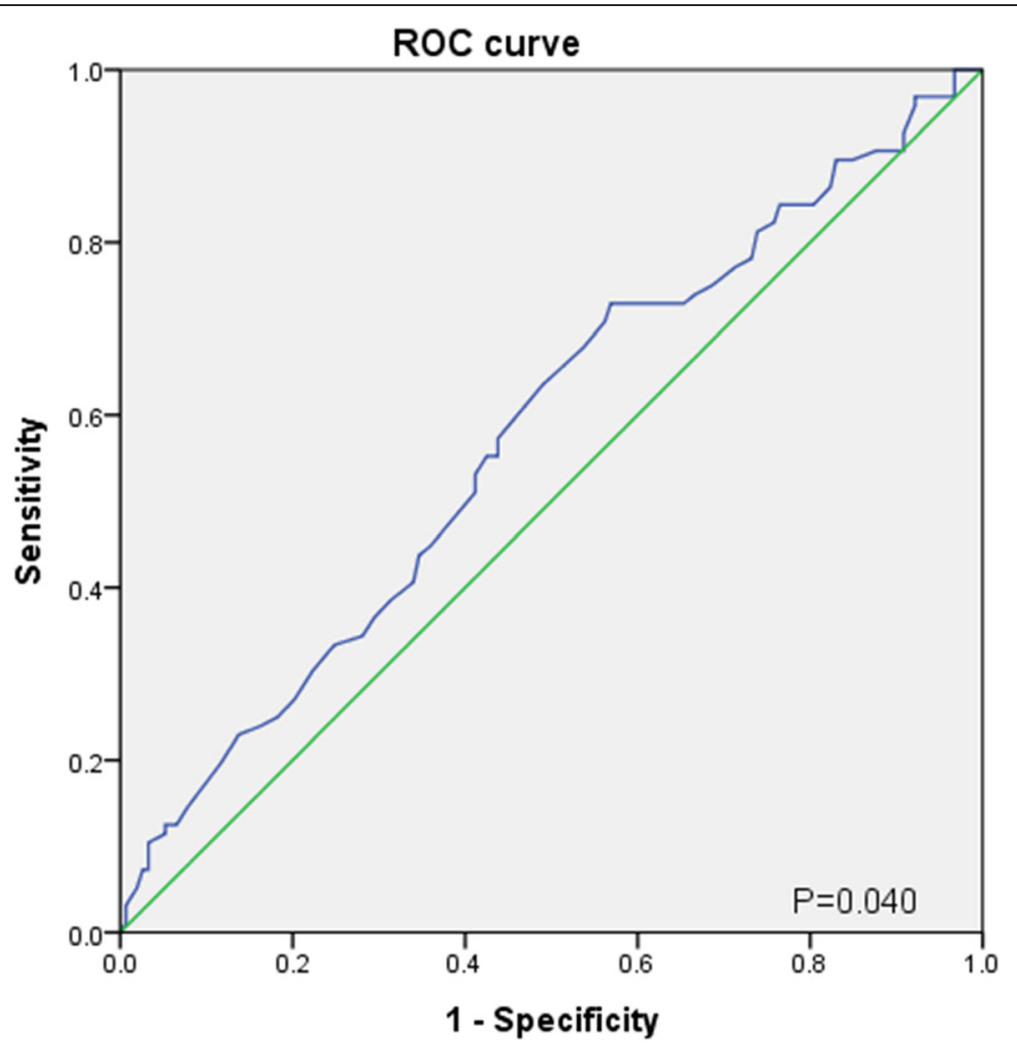

Fig. 2 ROC curve test for BEP as a predictor of requirement of additional oxygen supply. AEP: acute eosinophilic pneumonia; ROC curve: Receiver operating characteristic curve

respectively $(P=0.002)$ (Fig. $3 \mathrm{~b})$, while the mean number of steroid treatment days was $15.5,14.0$, and 12.6 , respectively $(P=0.006)$. The initial $\mathrm{PaO}_{2} / \mathrm{FiO}_{2}$ ratios were 249.7, 253.8, and 300.9, respectively $(P=0.003)$ (Fig. 3c).

\section{Association with significant oxygen requirements}

Age, CRP, smoking duration before admission, BEP, $\mathrm{PEC}$, and $\mathrm{BBE}$ score were entered into logistic regression analyses to determine the association with significant oxygen requirements (Table 3). CRP, BEP (categorical), PEC, and BBE scoring were significant in univariate analyses. Two models were applied for multivariate analyses. In model $1, \mathrm{BBE}$ scoring was entered, while BEP and PEC were excluded. In model 2, BEP and PEC were included, while BBE score was excluded. In model $1, \mathrm{BBE}$ score was the only significant factor associated with significant oxygen requirements $(P=$ $0.018)$. Compared to group with score 2 , the odds ratio (OR) for significant oxygen requirements was 2.25 (95\% confidence interval [CI]. 1.112-4.574, $P=0.024$ ) for group with score 1, while the OR was 3.014 (95\% CI 1.378-6.593, $P=0.006$ ) for group with score 2 . In model 2, BEP was a significant factor (OR 1.939, 95\% CI $1.072-3.505, P=0.028)$.

\section{Discussion}

The disease severity and clinical course of AEP vary in mild to severe cases, which may require no oxygen supply for mechanical ventilation. Therefore, it may be important to assess patients who are suspected of having AEP at initial presentation. However, it is difficult to reveal the prognostic factors of the disease statistically because it is a relatively rare disease. As patients from all military hospitals who are suspected of having AEP in South Korea are referred to the $\mathrm{AFCH}$, we were able to collect nationwide military data, although it was a single centre study. The development of AEP is associated with newly started or a recent resumption of cigarette smoking $[17,18]$. Many soldiers start or resume cigarette smoking, especially conscripted soldiers, as many have only recently attained the minimum age to consume cigarettes legally. Thus, we were able to enrol a sizable number of patients in this study.

We investigated factors that may affect disease severity and the clinical course of patients with AEP. Despite no statistical significance in multivariate analyses, we found an association between peripheral eosinophilia and decreased oxygen requirements in univariate analyses. Furthermore, PEC was negatively correlated with the number of oxygen supply days. Previous studies have 
Table 2 Comparison of clinical characteristics between three AEP groups stratified by the BAL/blood eosinophil score $(n=244)$

\begin{tabular}{|c|c|c|c|c|c|}
\hline & Overall patients & 0 & 1 & 2 & $P$-value \\
\hline Number of patients & 244 & 78 & 108 & 58 & - \\
\hline Sex (male) $(n, \%)$ & $243(99.6)$ & $78(100)$ & $108(100)$ & $57(98.3)$ & 0.200 \\
\hline Mean age (SD) & $20.4 \pm 1.5$ & $20.3 \pm 1.1$ & $20.5 \pm 1.9$ & $20.5 \pm 1.2$ & 0.488 \\
\hline Smoking history & & & & & 0.077 \\
\hline Ever smoker & 243 (99.6) & $78(100)$ & $108(100)$ & $57(98.3)$ & \\
\hline Never smoker & $1(0.4)$ & $0(0)$ & $0(0)$ & $1(1.7)$ & \\
\hline Cigarette smoking days & $26.9 \pm 26.9$ & $29.4 \pm 34.1$ & $24.8 \pm 24.4$ & $27.4 \pm 20.3$ & 0.545 \\
\hline WBC & $14,231 \pm 3888$ & $16,248 \pm 5005$ & $14,489 \pm 5130$ & $11,037 \pm 3888$ & $<0.001$ \\
\hline Peripheral eosinophil (\%) & $3.8 \pm 4.8$ & $1.5 \pm 1.0$ & $2.7 \pm 2.2$ & $9.0 \pm 7.1$ & $<0.001$ \\
\hline Peripheral eosinophil count & $419 \pm 419$ & $213 \pm 100$ & $318 \pm 199$ & $885 \pm 603$ & $<0.001$ \\
\hline BAL eosinophil (\%) & $46.8 \pm 17.8$ & $23.3 \pm 9.3$ & $53.4 \pm 14.2$ & $59.3 \pm 12.4$ & $<0.001$ \\
\hline BAL eosinophil count & $382 \pm 500$ & $154 \pm 137$ & $502 \pm 577$ & $469 \pm 558$ & $<0.001$ \\
\hline CRP (unit) & $9.5 \pm 5.5$ & $11.2 \pm 4.9$ & $10.2 \pm 5.7$ & $5.8 \pm 3.8$ & $<0.001$ \\
\hline Hospital days & $11.0 \pm 4.7$ & $12.4 \pm 6.3$ & $10.6 \pm 3.6$ & $10.1 \pm 3.6$ & 0.009 \\
\hline ICU admission & $96(39.8)$ & $33(42.3)$ & $55(50.9)$ & $8(13.8)$ & $<0.001$ \\
\hline ICU admission days & $2.0 \pm 1.3$ & $2.1 \pm 1.4$ & $1.9 \pm 1.2$ & $2.3 \pm 1.0$ & 0.731 \\
\hline PF ratio at admission & $261.9 \pm 73.4$ & $249.7 \pm 65.8$ & $253.8 \pm 79.0$ & $300.9 \pm 59.9$ & 0.003 \\
\hline O2 supply & & & & & 0.031 \\
\hline None & $52(21.3)$ & $11(14.1)$ & $20(18.5)$ & $21(36.2)$ & \\
\hline Nasal or mask only & $184(75.4)$ & $63(80.8)$ & 86 (79.6) & $35(60.3)$ & \\
\hline Mechanical ventilation & $3(1.2)$ & $2(2.6)$ & $1(0.9)$ & $0(0.0)$ & \\
\hline HFNC & $5(2.0)$ & $2(2.6)$ & $1(0.9)$ & $2(3.4)$ & \\
\hline Oxygen supply days & $2.9 \pm 1.5$ & $3.4 \pm 1.6$ & $2.8 \pm 1.4$ & $2.3 \pm 1.5$ & 0.002 \\
\hline Steroid treatment days & $14.3 \pm 5.2$ & $15.5 \pm 5.8$ & $14.0 \pm 4.7$ & $12.6 \pm 4.7$ & 0.006 \\
\hline
\end{tabular}

Abbreviations: BAL Bronchoalveolar lavage, CRP C-reactive protein, HFNC High-flow nasal cannula, ICU Intensive care unit, PF ratio PaO2/FiO2, SD Standard deviation, WBC White blood cell

reported that patients with initial peripheral eosinophilia undergo a mild disease course compared to patients with normal levels of eosinophils [12, 13].

The exact mechanism of this association has not been revealed; however, it may be associated with cytokines, such as interleukin (IL)-5, which have an inverse correlation with PEC [19]. As IL-5 is an important mediator of recruitment of eosinophils from peripheral blood into the lungs, a decrease in IL-5 may attenuate eosinophilic inflammation in the lung. In addition, PEC tends to increase during the course of AEP [3, 20-24]. This suggests that patients with initial peripheral eosinophilia may present to the medical centre at a later course of the disease than patients with a normal PEC. As the prognosis of AEP was favourable in this subgroup of our patients, we assumed that patients with initial peripheral eosinophilia already passed the peak of disease activity before admission and were admitted at a later course of the disease.

BEP may also predict clinical outcomes. Our results are in line with a previous study that showed that patients with peripheral eosinophilia have a significantly higher BEP [12]. Furthermore, Sine et al. revealed a positive correlation between BAL eosinophilia and the $\mathrm{PaO}_{2}$ / $\mathrm{FiO}_{2}$ ratio in patients with AEP [13]. In our study, we found that $\mathrm{BEP}$ was positively correlated with $\mathrm{PaO}_{2} / \mathrm{FiO}_{2}$ but negatively correlated with total oxygen supply days, suggesting that patients with higher BEP may experience a milder clinical course. Moreover, an increase in BEP was independently associated with decreased oxygen requirements. However, the correlation coefficients were weak to suggest strong correlations, which should be taken into account.

Using PEC alone, a previous study was unable to predict important outcomes, such as the number of hospital days or the $\mathrm{PaO} 2 / \mathrm{FiO} 2$ ratio [10]. In our study, we also evaluated the association between the combination of the two parameters (BEP an PEC) and clinical outcomes. After stratifying by BBE score, group with score 2 (elevated BEP and PEC) had a lower CRP, hospital days, ICU admission, $\mathrm{PaO}_{2} / \mathrm{FiO}_{2}$ ratio, total oxygen supply days, and steroid treatment days compared to 
(A)

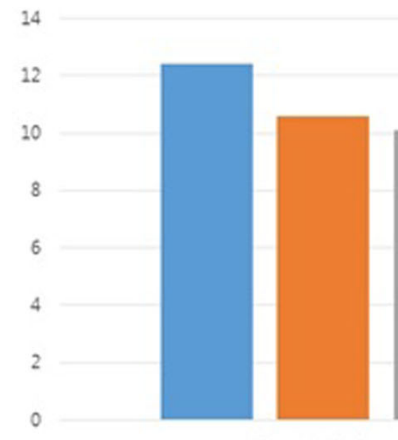

Hospital days
$P=0.009$

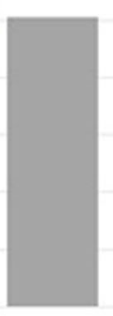

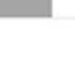

(B)

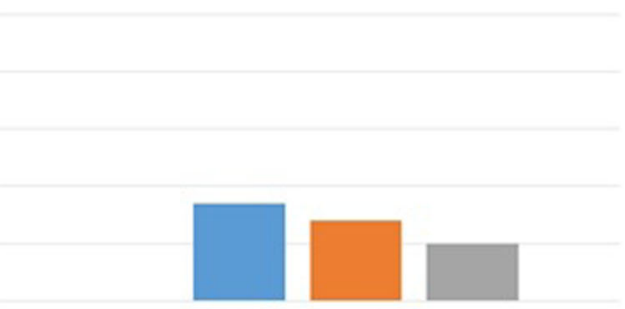

Oxygen supply days

$0=1=2$
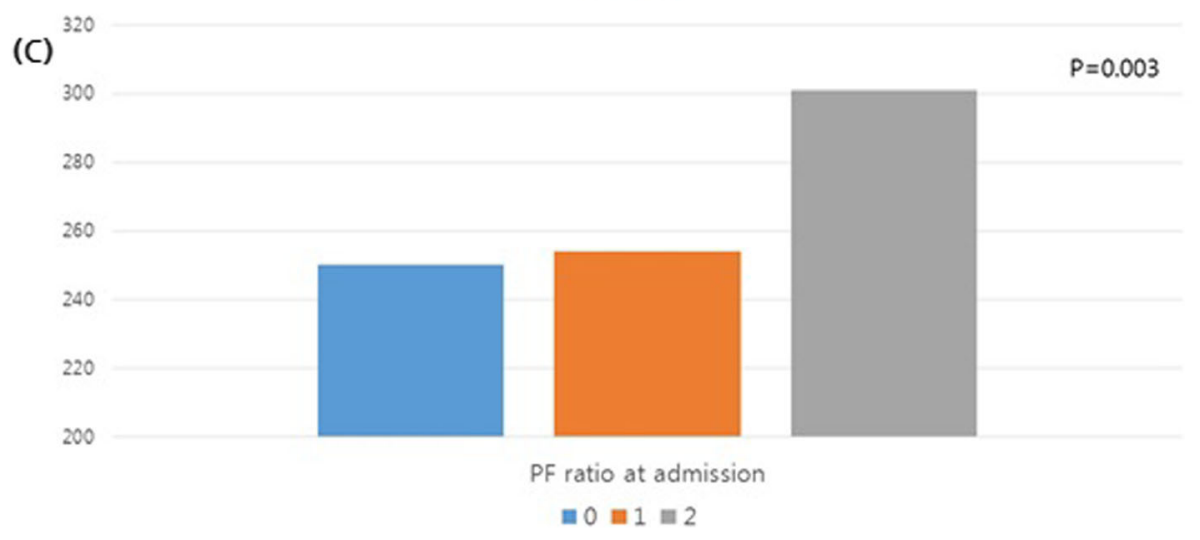

Fig. 3 Comparison of clinical parameters between the three AEP groups stratified by the BAL/blood eosinophil score, a) hospital days, (b) oxygen supply days, and (c) $\mathrm{PaO}_{2} / \mathrm{FiO}_{2}$ at admission. AEP: acute eosinophilic pneumonia; $\mathrm{BAL}$ : bronchoalveolar lavage; PF ratio: PaO2/FiO2. The English in this document has been checked by at least two professional editors, both native speakers of English. For a certificate, please see: http://www.textcheck.com/certificate/XxOLy1

the other groups. Multiple logistic regression models revealed that BBE score was the only factor that predicted a lower chance of a significant oxygen requirement. Nevertheless, the application of BBE scoring to other AEP population needs further validation process, because the cut-off used to categorize BEP into high/ low group could be different in other patients group. However, our findings suggest that elevated BEP and PEC result in a more favourable clinical outcome in patients with AEP.

Table 3 Patient factors analysis showing association with significant oxygen requirements

\begin{tabular}{|c|c|c|c|c|c|c|c|c|c|}
\hline \multirow[b]{2}{*}{ Characteristics } & \multicolumn{3}{|c|}{ Univariate } & \multirow{2}{*}{$\begin{array}{l}\text { Multiple } \\
\text { OR }\end{array}$} & \multirow{2}{*}{$\begin{array}{l}\text { (Model 1) } \\
95 \% \mathrm{Cl}\end{array}$} & \multirow[b]{2}{*}{$P$} & \multirow{2}{*}{$\begin{array}{l}\text { Multiple } \\
\text { OR }\end{array}$} & \multirow{2}{*}{$\begin{array}{l}\text { (Model 2) } \\
95 \% \mathrm{Cl}\end{array}$} & \multirow[b]{2}{*}{$P$} \\
\hline & $\overline{\mathrm{OR}}$ & $95 \% \mathrm{Cl}$ & $P$ & & & & & & \\
\hline $\mathrm{Age}^{\mathrm{a}}$ & 1.140 & $0.969-1.363$ & 0.13 & 1.229 & $0.972-1.553$ & 0.084 & 1.226 & $0.974-1.543$ & 0.083 \\
\hline CRP & 1.070 & $1.020-1.110$ & 0.009 & 1.022 & $0.968-1.078$ & 0.432 & 1.026 & $0.972-1.083$ & 0.356 \\
\hline Smoking duration & 1.006 & $0.997-1.016$ & 0.201 & - & - & - & - & - & - \\
\hline BAL eosinophil \% (High/low) & 0.490 & $0.282-0.851$ & 0.011 & & & & 0.516 & $0.285-0.933$ & 0.028 \\
\hline Peripheral eosinophil count (High/low) & 0.497 & $0.283-0.873$ & 0.015 & & & & 0.679 & $0.358-1.286$ & 0.234 \\
\hline \multicolumn{10}{|l|}{ Blood/BAL scoring } \\
\hline 0 & 3.187 & $(1.567-6.484)$ & 0.001 & 3.014 & $1.378-6.593$ & 0.006 & & & \\
\hline 1 & 2.610 & $(1.356-5.024)$ & 0.004 & 2.256 & $1.112-4.574$ & 0.024 & & & \\
\hline 2 & 1 & - & 0.003 & 1 & - & 0.018 & & & \\
\hline
\end{tabular}

a For every 1 year increase

Model 1: Blood/BAL scoring is entered for multivariate analysis

Model 2: BAL eosinophil (\%) (High/low) and blood eosinophil count were entered for multivariate analysis. Blood/BAL scoring were excluded from analysis Abbreviations: BAL Bronchoalveolar lavage, CRP C-reactive protein 
Some limitations of our study should be discussed. First, as we used retrospective data, the possibility of selection bias or observer bias should be considered. Second, we defined "significant oxygen requirement" as the total number of days of oxygen supplied equal to 2 days or more during admission. Although this definition was made after considering the possibility of an oxygen supplement related to bronchoscopy, whether this definition is appropriate should be validated in future studies. Third, patients with a milder clinical course may not have presented to our hospital. AEP with mild symptoms and little or no hypoxemia may resolve without treatment. Therefore, some patients with a mild clinical course may have been neglected as they may have not presented to our centre. Fourth, the AUC obtained from ROC curve analysis, while determining the optimal cutoff value of BEP for prediction of significant oxygen requirement was relatively low (AUC $=0.577$ ). Finally, as our study was performed in a military hospital, the enrolled patients were mostly young males. Thus, our study population may not be representative of the general population. However, as smoking-related AEP is likely to develop soon after patients start to smoke, our results retain clinical importance.

\section{Conclusions}

In conclusion, AEP patients with both peripheral and BAL eosinophilia at presentation have more favourable outcomes. Prospective studies that apply this scoring system to different AEP populations are necessary for further clinical application.

\section{Abbreviations \\ AEP: Acute eosinophilic pneumonia; AFCH: The army forces capital hospital; BAL: Bronchoalveolar lavage; BBE score: BAL/blood eosinophil score; BEP: Bronchoalveolar lavage eosinophil percentage; CRP: C-reactive protein; EMR: Electronic medical records; FiO2: Inspiratory oxygen fraction; HFNC: High-flow nasal cannula; ICU: Intensive care unit; IL-5: Interleukin-5; PACS: Picture archiving and communication system; PaO2: Arterial oxygen tension; PEC: Peripheral eosinophil count.; ROC: Curve receiver operating characteristic curve.; WBC: White blood cell.}

\section{Acknowledgements}

No specific acknowledgements.

\section{Authors' contributions}

CJY: Substantial contribution to the conception, study design, interpretation of data, drafted work and revision. LU: Substantial contribution to the conception, study design, analysis, drafted work and revision. JHJ: substantial contribution to the study design and analysis. LJE: Study design and interpretation of data. RCK: Contribution to the study design, data analysis, drafting, revision, final approval, and accountability of all aspects of the work. All authors have approved the final version of the work.

\section{Funding}

None.

\section{Availability of data and materials}

The database used in this study are available from the corresponding author on reasonable request.

\section{Ethics approval and consent to participate}

The study was approved by the Ethics Committee of the AFCH (AFCH-18IRB-008). Informed consent was waived because of the retrospective nature of this study. Accessibility of the database and data review was permitted by the Ethics Committee of the AFCH.

\section{Consent for publication}

Not applicable.

\section{Competing interests}

The authors declare that they have no competing interests.

\section{Author details}

${ }^{1}$ Division of Pulmonary, Allergy and Critical Care Medicine, Department of Internal Medicine, St. Vincent's Hospital, College of Medicine, The Catholic University of Korea, Suwon, Republic of Korea. ${ }^{2}$ Division of Pulmonary, Allergy and Critical Care Medicine, Department of Internal Medicine, Seoul St. Mary's Hospital, College of Medicine, The Catholic University of Korea, Seoul, Republic of Korea. ${ }^{3}$ Division of Pulmonary and Critical Care Medicine, Department of Medicine, The Armed Forces Capital Hospital, Seongnam, Republic of Korea, 222, Banpo-daero Seocho-gu, Seoul 06591, Republic of Korea.

Received: 4 June 2019 Accepted: 17 January 2020

Published online: 28 January 2020

\section{References}

1. Allen JN, Pacht ER, Gadek JE, Davis WB. Acute eosinophilic pneumonia as a reversible cause of noninfectious respiratory failure. N Engl J Med. 1989; 321(9):569-74

2. Badesch DB, King TE Jr, Schwarz MI. Acute eosinophilic pneumonia: a hypersensitivity phenomenon? Am Rev Respir Dis. 1989;139(1):249-52.

3. Shorr AF, Scoville SL, Cersovsky SB, Shanks GD, Ockenhouse CF, Smoak BL, Carr WW, Petruccelli BP. Acute eosinophilic pneumonia among US military personnel deployed in or near Iraq. Jama. 2004:292(24):2997-3005.

4. Rhee CK, Min KH, Yim NY, Lee JE, Lee NR, Chung MP, Jeon K. Clinical characteristics and corticosteroid treatment of acute eosinophilic pneumonia. Eur Respir J. 2013;41(2):402-9.

5. Philit F, Etienne-Mastroianni B, Parrot A, Guerin C, Robert D, Cordier JF. Idiopathic acute eosinophilic pneumonia: a study of 22 patients. Am J Respir Crit Care Med. 2002;166(9):1235-9.

6. Lim SY, Suh GY, Jeon K. Acute eosinophilic pneumonia presenting as lifethreatening hypoxaemia necessitating extracorporeal membrane oxygenation. Int J Tuberc Lung Dis :Official J Int Union Against Tuberc Lung Dis. 2012;16(12):1711-2.

7. Kawayama T, Fujiki R, Morimitsu Y, Rikimaru T, Aizawa H. Fatal idiopathic acute eosinophilic pneumonia with acute lung injury. Respirology (Carlton, Vic). 2002;7(4):373-5.

8. Jhun BW, Kim SJ, Son RC, Yoo H, Jeong BH, Chung MP, Jeon K. Clinical outcomes in patients with acute eosinophilic pneumonia not treated with corticosteroids. Lung. 2015;193(3):361-7.

9. Lee JE, Rhee CK, Lim JH, Lee SM, Shim YS, Lee CT, Lee SW. Fraction of exhaled nitric oxide in patients with acute eosinophilic pneumonia. Chest. 2012;141(5):1267-72

10. Yoon CG, Kim SJ, Kim K, Lee JE, Jhun BW. Clinical characteristics and factors influencing the occurrence of acute Eosinophilic pneumonia in Korean military personnel. J Korean Med Sci. 2016;31(2):247-53.

11. Jhun BW, Kim SJ, Kim K, Lee JE: Outcomes of rapid corticosteroid tapering in acute eosinophilic pneumonia patients with initial eosinophilia. Respirology (Carlton, Vic) 2015, 20('):1241-1247.

12. Jhun BW, Kim SJ, Kim K, Lee JE. Clinical implications of initial peripheral eosinophilia in acute eosinophilic pneumonia. Respirology (Carlton, Vic). 2014;19(7):1059-65.

13. Sine CR, Hiles PD, Scoville SL, Haynes RL, Allan PF, Franks TJ, Morris MJ, Osborn EC. Acute eosinophilic pneumonia in the deployed military setting. Respir Med. 2018;137:123-8.

14. O'Driscoll BR, Howard LS, Earis J, Mak V. British Thoracic Society guideline for oxygen use in adults in healthcare and emergency settings. BMJ Open Respir Res. 2017:4(1):e000170. 
15. Nishimura M. High-flow nasal cannula oxygen therapy in adults: physiological benefits, indication, clinical benefits, and adverse effects. Respir Care. 2016;61 (4):529-41.

16. Du Rand IA, Blaikley J, Booton R, Chaudhuri N, Gupta V, Khalid S, Mandal S, Martin J, Mills J, Navani N, et al. Summary of the British Thoracic Society guideline for diagnostic flexible bronchoscopy in adults. Thorax. 2013;68(8): 786-7.

17. Takeuchi A, Nelson C, Yamamoto I, Yamashiro S, Myers J. Acute Eosinophilic pneumonia after resumption of cigarette smoking. Mil Med. 2016;181(6): e613-5.

18. Thakur LK, Jha KK. Acute eosinophilic pneumonia following recent cigarette smoking. Respir Med Case Rep. 2016;19:103-5.

19. Jhun BW, Kim SJ, Kim K, Lee JE, Hong DJ. Clinical implications of correlation between peripheral eosinophil count and serum levels of IL-5 and tryptase in acute eosinophilic pneumonia. Respir Med. 2014;108(11):1655-62.

20. Kitahara Y, Matsumoto K, Taooka Y, Moritani C, Nakamura K, Ohashi N, Daido K, Arita K. Cigarette smoking-induced acute eosinophilic pneumonia showing tolerance in broncho-alveolar lavage findings. Intern Med (Tokyo, Japan). 2003;42(10):1016-21.

21. Shiota Y, Kawai T, Matsumoto H, Hiyama J, Tokuda Y, Marukawa M, Ono T, Mashiba $\mathrm{H}$. Acute eosinophilic pneumonia following cigarette smoking. Intern Med (Tokyo, Japan). 2000;39(10):830-3.

22. Rom WN, Weiden M, Garcia R, Yie TA, Vathesatogkit P, Tse DB, McGuinness G, Roggli V, Prezant D. Acute eosinophilic pneumonia in a New York City firefighter exposed to world trade center dust. Am J Respir Crit Care Med. 2002;166(6):797-800

23. Uchiyama H, Suda T, Nakamura Y, Shirai M, Gemma H, Shirai T, Toyoshima M, Imokawa S, Yasuda K, Ida M, et al. Alterations in smoking habits are associated with acute eosinophilic pneumonia. Chest. 2008;133(5):1174-80.

24. Watanabe K, Fujimura M, Kasahara K, Yasui M, Myou S, Kita T, Watanabe A, Nakao S. Acute eosinophilic pneumonia following cigarette smoking: a case report including cigarette-smoking challenge test. Intern Med (Tokyo, Japan). 2002:41(11):1016-20.

\section{Publisher's Note}

Springer Nature remains neutral with regard to jurisdictional claims in published maps and institutional affiliations.

Ready to submit your research? Choose BMC and benefit from:

- fast, convenient online submission

- thorough peer review by experienced researchers in your field

- rapid publication on acceptance

- support for research data, including large and complex data types

- gold Open Access which fosters wider collaboration and increased citations

- maximum visibility for your research: over $100 \mathrm{M}$ website views per year

At $\mathrm{BMC}$, research is always in progress.

Learn more biomedcentral.com/submissions 